\title{
Enhancing Older Adults' Wellbeing and Quality of Life through Purposeful Activity: A Systematic Review of Intervention Studies
}

\author{
Document Version \\ Accepted author manuscript
}

Link to publication record in Manchester Research Explorer

Citation for published version (APA):

Owen, R., Berry, K., \& Brown, L. J. E. (2021). Enhancing Older Adults' Wellbeing and Quality of Life through Purposeful Activity: A Systematic Review of Intervention Studies. The Gerontologist.

\section{Published in:}

The Gerontologist

\section{Citing this paper}

Please note that where the full-text provided on Manchester Research Explorer is the Author Accepted Manuscript or Proof version this may differ from the final Published version. If citing, it is advised that you check and use the publisher's definitive version.

\section{General rights}

Copyright and moral rights for the publications made accessible in the Research Explorer are retained by the authors and/or other copyright owners and it is a condition of accessing publications that users recognise and abide by the legal requirements associated with these rights.

\section{Takedown policy}

If you believe that this document breaches copyright please refer to the University of Manchester's Takedown Procedures [http://man.ac.uk/04Y6Bo] or contact uml.scholarlycommunications@manchester.ac.uk providing relevant details, so we can investigate your claim.

\section{OPEN ACCESS}


Title: Enhancing Older Adults' Wellbeing and Quality of Life through Purposeful Activity: A Systematic Review of Intervention Studies

\author{
Dr Rebecca Owen $\mathrm{PhD}^{1}$ \\ Prof Katherine Berry $\mathrm{PhD}^{1}$ \\ *Dr Laura J.E. Brown $\mathrm{PhD}^{1}$
}

This is a pre-copyedited, author-produced PDF of an article accepted for publication in the journal

The Gerontologist. The doi of the final published version of the article (Owen et al., 2021) is:

$\underline{10.1093 / \text { geront/gnab017 }}$

${ }^{1}$ Division of Psychology and Mental Health, School of Health Sciences, Faculty of Biology, Medicine and Health, University of Manchester, Manchester Academic Health Sciences Centre, UK

*Corresponding author: Laura Brown (laura.brown@manchester.ac.uk) 


\section{Funding}

No external funding was received.

\section{Conflict of Interest}

The authors report no conflict of interest. 


\begin{abstract}
Background and Objectives: Population aging represents a significant challenge for health and social care services. Older adults who engage in activities that offer a sense of purpose have significantly better physical and psychological health outcomes. However, age-related functional limitations and losses of social roles can present barriers to engaging in purposeful activity, especially for those older adults within the 'oldest old' age range (i.e. 80 years and over). This review aimed to determine the nature and effectiveness of purposeful activity interventions in older adults, aged $\geq 80$ years, with respect to wellbeing and quality of life outcomes.

Research Design and Methods: Three databases were searched from their inception to April 2020. The search yielded 8,916 records, which resulted in eight eligible studies.

Results: The interventions were divided into two groups: (1) interventions that gave participants a specific functional role, such as volunteer or mentor $(n=5) ;(2)$ interventions that supported participants to develop a new skill $(n=3)$. The quality of the evidence was variable. The strongest evidence was for interventions that assigned a functional role, which appeared to be somewhat effective in improving wellbeing outcomes.

Discussion and Implications: There is preliminary evidence that purposeful activity interventions, particularly those that involved taking on a functional role, can improve wellbeing and quality of life outcomes in older adults aged 80 years and over. These findings have implications for professionals and carers to support older adults to access more purposeful social roles, and create opportunities for helping and reciprocation.
\end{abstract}

Key Words: Meaningful activity; psychosocial; oldest old; volunteering; social role

\title{
Background and Objectives
}


The process of ageing is highly heterogeneous, with a significant level of variation in older adults' physical, social, and psychological domains of functioning (Cosco, Howse \& Brayne, 2017). For example, research has demonstrated that older adults can function successfully despite declining physical health and chronic disease pathology (Depp \& Jeste, 2006; Depp, Vahia \& Jeste, 2010), whereas some older adults without chronic conditions can exhibit high levels of disability (Verropoulou \& Tsimbos, 2017). This suggests that, although disease conditions and physical impairments are related to an individual's level of functioning in later life, they are not sufficient to fully explain the causes of disability.

The main pathway of the Disablement Model (Femia, Zarit \& Johansson, 2001; Verbrugge \& Jette, 1994) proposes that disability is predicted by functional impairments (i.e., dysfunctions in bodily systems such as cardiovascular, neurological, musculoskeletal, and pulmonary systems), which, in turn, lead to functional limitations, such as poor mobility. However, this pathway to disability is moderated by psychosocial factors and internal resources, such as social support, quality of life and emotional wellbeing. A test of the model in 203 participants aged 80 and over indicated that modifying psychosocial factors, such as social integration and depression, significantly affected the disablement process (Femia, Zarit \& Johansson, 2001). Given such findings, and the growing recognition of the reciprocal relationship between physical and psychological health (e.g., An \& Jang, 2018; Ohrnberger, Fichera \& Sutton, 2017), interventions that seek to promote increased psychological wellbeing and quality of life in older adults are clearly warranted.

Researchers have attempted to understand the factors that may contribute to improved quality of life and wellbeing in later life, in order to address the changing needs of older populations. It has been proposed that maintaining a sense of purpose may facilitate resilience against adverse life events and stress, which may offer some insight into how and why certain people remain healthy over time and age successfully (McKnight \& Kashdan, 2009). For example, there is evidence to suggest that older adults who engage in activities that provide them with a sense of purpose tend to have significantly better physical and psychological health outcomes than those who do not (Irving, Davis \& Collier, 2017; Kim et al., 2013). A sense of purpose in older age can be cultivated from numerous sources, including the pursuit of personal goals or plans, structured community engagement, adopting meaningful social roles, and participation in activities that provide a sense of achievement or facilitate feelings of usefulness (e.g., Heaven et al., 2013; Irving, Davis \& Collier 2017). For example, previous studies have demonstrated that volunteering is associated with better self-reported health ratings in older adults (Morrow-Howell, Hinterlong, Rozario, \& Tang, 2003), increased life satisfaction (Van 
Willigen, 2000), personal independence (Morrow-Howell et al., 2003) and even decreased mortality rates (Konrath, Fuhrel-Forbis, Lou, \& Brown, 2012; Shmotkin, Blumstein, \& Modan, 2003). Furthermore, a recent systematic review demonstrated that older adults who appraised themselves as having a higher sense of purpose had significantly better overall physical health, lower cognitive impairment, reduced depression and engaged in more preventative health behaviours (Irving, Davis \& Collier, 2017). This suggests that purposeful activity may represent a modifiable factor that has the potential to protect against some of the challenges of ageing.

Despite the promising benefits of engagement in purposeful activity, older adults can experience great difficulty maintaining a sense of purpose due to age-related losses of independence and relationships, and the experience of physical, cognitive and sensory impairments, which may prevent them from performing activities that previously provided a sense of purpose (Bronk, 2014; Pinquart, 2002; Sarvimaki \& Stenbock-Hult, 2000). These barriers are particularly pertinent to the 'oldest old' (those aged $\geq 80$ ), who typically have a greater number of risk factors for disability (e.g., chronic conditions and functional impairments) than older adults aged between 65 and 80 (e.g., Fortin et al., 2005; Landi et al., 2010). This represents a key challenge for health care professionals and social care providers when attempting to engage the oldest old in interventions that aim to promote purposeful activity.

Within the current literature, there is no systematic review of the nature and effectiveness of studies that have implemented a purposeful activity intervention in the oldest old. As well as providing researchers and practitioners with an idea of the types of intervention that have been developed for this population, such a review is needed in order to determine how effective such interventions could be in improving older adults' wellbeing and quality of life. Therefore, the aims of the present review were, (1) to ascertain what types of purposeful activity interventions have been implemented with older adults in the oldest old age range (i.e. aged $\geq 80$ ) within the existing research literature; (2) to determine whether these interventions significantly improved wellbeing and quality of life outcomes in the oldest old.

\section{Research Design and Methods}

A protocol for this review was submitted to PROSPERO (the International prospective register of systematic reviews) on $7^{\text {th }}$ Jan 2020, when only the preliminary searches had started, but the registration process was not completed. A copy of the information submitted to PROSPERO 
is available on request. The manuscript was written in line with the Preferred Reporting Items for Systematic Reviews and Meta-Analyses (PRISMA) checklist (www.prisma-statement.org).

\section{Inclusion and Exclusion Criteria}

To be included in the review, reports had to be published in the English language and conform to the following criteria:

1. The study sample was comprised of older adults within the 'oldest old' age-range. This was operationalised as having a sample with a mean age of 80 years or above (United Nations (UN) agreed cut-off for the 'oldest old' population; UN, 2017). There were no exclusion criteria relating to the presence of cognitive impairment or other health conditions, or the setting in which participants lived, i.e., both community-dwelling older adults and those residing in residential care homes were eligible for inclusion.

2. The study included an intervention in which participants were supported to engage in purposeful activities. Purposeful activities were defined as activities with clearly discernible goals or aims that offer a sense of directionality towards a specific outcome (e.g., Pierce, 2001; Schulenberg \& Melton, 2010), such as learning a new skill or volunteering to help others. Interventions comprising of activities where the primary aim was solely to enhance participants' enjoyment or pleasure, such as, attending social clubs, arts and crafts, reading and walking, were not included. If the intervention was not explicitly labelled or described as being a 'purposeful activity' in the study, but was considered by the primary reviewer to match the definition, then the study was shared with another member of the review team so that a consensus decision could be made. This approach was adopted in order to minimise the omission of relevant studies because of differences in terminology or reporting style (Heaven et al., 2013).

3. The study included at least one standardised measure of quality of life or wellbeing, including mood and life satisfaction: both components of subjective wellbeing (Brown \& Astell, 2012), as well as clinical depression and anxiety scales. Both self-report and observerrated measures were eligible for inclusion. 
Whilst we originally intended to limit the review to studies published as journal articles, the low number of eligible studies identified through our preliminary searches led us to expand the scope of the review to also include work published in $\mathrm{PhD}$ theses.

\section{Search Strategy}

A systematic literature search was performed in three electronic databases (Ovid Medline, PsycInfo, and CINAHL) between October and April 2020. The search strategy was initially developed for the Ovid database and subsequently adapted to fit other databases, as appropriate. Search terms related to the population (e.g., older adult* OR senior citizen* OR care home*), presence of an intervention (e.g., interven* OR program* OR treatment), the focus of the intervention (e.g., purposeful activit* OR volunt* OR role*) and the outcome (e.g., quality of life OR well-being OR life satisfact*) were combined with the Boolean operator 'AND'. See supplementary table 1 for the full list of search terms.

The database search results were exported into Endnote reference management software to organise the search and remove duplicates. After 314 duplicates were removed, the search yielded 8,916 records. The tiles and abstracts of these records were first screened by the first author to identify and exclude those that clearly did not meet the inclusion criteria. A second reviewer, independent from the research team, also screened $10 \%(\mathrm{~N}=892)$ of records from the initial search by title and abstract, in order to ensure reliability of the screening process. As the level of agreement was high $(98 \%, \mathrm{k}=.70)$ the remaining $90 \%$ of records were screened by just the first author.

A total of 8799 records were excluded during this initial screening phase, leaving 117 records to be reviewed at full-text level. All of these were independently reviewed against the inclusion criteria by the first author and the second reviewer. Authors of study reports were contacted in cases where insufficient information was available to determine eligibility. A high level of consistency between reviewers was attained ( $99 \%$ agreement, $\mathrm{k}=.86$ ), and all discrepancies were resolved through discussion between the two reviewers and the other study authors. One hundred and nine records were excluded at this stage, leaving eight that were deemed eligible for inclusion. Reference lists and citations of these included studies were then searched for any additional studies that may have met the inclusion criteria, but no eligible studies were identified. Figure 1 illustrates the selection of studies through the different phases of the systematic search. 
Insert Figure 1 about here

\section{Data Extraction}

Data relating to each of the fields listed in Table 1 were extracted by the first author.

\section{Quality Assessment}

The methodological quality of all included studies was assessed using the Effective Public Health Practice Project (EPHPP) Quality Assessment Tool for Quantitative Studies (Thomas, Ciliska, Dobbins \& Micucci, 2004), which has previously demonstrated good reliability and validity (Armijo-Olivo, Stiles, Hagen, Biondo, \& Cummings, 2012; Thomas, Ciliska, Dobbins, \& Micucci, 2004). Consistent with more recent systematic reviews (Degnan et al., 2018; Safavi, Berry, \& Wearden, 2017), the tool was adapted to include a component assessing the quality of analysis, which took into account factors such as the power and appropriateness of the analyses. This adapted version of the EPHPP therefore included the following seven components: (1) selection bias, (2) study design, (3) confounders, (4) blinding, (5) data collection, (6) data analysis, and (7) withdrawals and drop-outs. Each component was rated as either 'strong', 'moderate' or 'weak'. The scores were averaged to provide a total score, and each study assigned an overall quality rating.

The first author and a second, independent, reviewer independently performed quality ratings for all eight studies. There was a satisfactory level of agreement for overall quality ratings $(75 \% ; \mathrm{k}=0.50)$. Discrepancies were discussed with the wider research team, and a final decision was reached for each study.

\section{Evidence Synthesis}

There was a marked level of heterogeneity within the methodologies, interventions, and outcome measures across studies, which meant that a meta-analysis was not appropriate. A narrative synthesis of the evidence (Mays, Roberts, \& Popay, 2001) was therefore conducted instead. This evidence synthesis took into consideration the characteristics and quality of each study, as well as the findings. Following the guidelines of Popay et al., (2006), the evidence synthesis had three key stages: (1) The studies were organised into logical categories: in this case, i.e., intervention types; (2) The main findings from each study were presented (i.e., within-study synthesis; see Table 1); (3) Differences in study characteristics and potential 
sources of bias were integrated, and the range of effects were described (i.e., cross-study synthesis).

\section{Results}

Eight publications (seven journal articles and one PhD thesis) were included in the review. Four of the studies described in the publications were conducted in the United States (Yuen, 2003; Yuen et al., 2008; George \& Singer, 2011; Klinedinst \& Resnick, 2016), one in Canada (Kiyota, 2009), one in Croatia (Kosmat \& Vranic, 2017), one in Italy (Sollami et al., 2017), and one in Belgium (Van Malderen et al., 2017). Collectively, the interventions covered a 14year period, from 2003 to 2017 . There were five individually or cluster randomised-controlled trials (George \& Singer, 2011; Kiyota, 2009; Kosmat \& Vranic, 2017; Sollami et al., 2017; Van Malderen et al., 2017; Yuen et al., 2008); one controlled clinical trial (Yuen, 2003) and one uncontrolled cohort study (Klinedinst \& Resnick, 2016). Sample sizes of the included studies ranged from 10 (Klinedinst \& Resnick, 2016) to 88 (Van Malderen et al., 2017). All studies were conducted with participants residing in residential care homes, nursing homes and/or assisted-living facilities i.e., community-dwelling older adults were not participants in any study. All interventions were delivered within a single site, except one which was conducted across three separate nursing homes (Van Malderen et al., 2017).

\section{Intervention Types}

Studies were grouped according to two broad intervention types; (1) interventions that assigned participants a specific functional role; (2) interventions that taught participants a new skill. Five studies evaluated an intervention that assigned participants a specific functional role, which were: becoming mentors to assist pre-school children with their reading and writing in an intergenerational volunteering program (George \& Singer, 2011); becoming volunteers for local charitable organisations (VIP; Klinedinst \& Resnick, 2016); becoming a member of a nursing home steering committee (PAR; Van Malderen et al., 2017); and acting as mentors to English as a Second Language (ESL) students to help them improve their conversational skills (Yuen, 2003; Yuen et al., 2008). Three studies evaluated an intervention that trained participants in the development of a new skill, which were: learning to dance (Kosmat \& Vranic, 2017); learning how to care for and train a dog (Sollami et al., 2017); and learning how to undertake indoor gardening (Kiyota, 2009). Table 1 below outlines the study characteristics and main findings, grouped according to intervention type. 
Insert Table 1 about here

\section{Quality Assessment}

Global quality ratings (Table 1) ranged from weak to strong, with the most common global rating being 'moderate' (50\%). Two studies (George \& Singer, 2011; Yuen et al., 2008) were rated as 'strong' (25\%) based on factors including a robust study design, control for a range of potential confounding variables, and high study retention rates. Two studies (Sollami et al., 2017; Yuen, 2003) were rated as 'weak' (25\%), partly due to a lack of reported information to ascertain whether particular criteria were fulfilled and high drop-out rates. Many studies did not include sufficient information regarding whether potential confounding variables were controlled for, or whether researchers had been blind to group allocation. Quality ratings for each component of the EPHPP can be found in Supplementary Table 2.

\section{Evidence Synthesis}

\section{Interventions that assigned a specific functional role}

Collectively, the studies in this group demonstrated some evidence in favour of functional role interventions having a positive effect on wellbeing outcomes (see Table 1). Specifically, four of the five studies in this group showed evidence of an increase in at least one wellbeing outcome in the intervention group; one study showed no significant effects in any group; and no study showed evidence of the intervention causing a reduction in wellbeing. Of the four interventions showing positive effects: one (George \& Singer, 2011) showed a significant effect of a school-child mentoring programme on just one of the two outcome measures. Moreover, although the quality of this study was rated as strong, the very small sample of just 15 participants across two groups increases the risk of both false positive and false negative results. The study by Yuen (2003) showed a significant improvement in life satisfaction for participants involved in a mentoring programme for students learning English as a second language that was not seen in the control group. However, this study was rating as being of weak quality; had a small sample size of just 18 participants across two groups; and used a passive (usual care) rather than an active control, making it difficult to precisely determine what the active ingredient(s) of the intervention were. A subsequent study by the same group (Yuen et al., 2008) was rated as being of strong quality. However, the significant improvement in global wellbeing seen in the intervention group was also found in the passive (usual care) control group, suggesting that the intervention itself had limited or no specific effect. Finally, 
the study by Van Maldern et al. (2017), investigating the effects of being part of a participatory action research group, had a larger sample size, and was rated as being moderate in quality. However, the significant effect seen in this study was also seen in the active (but not passive) control condition, which comprised of a weekly reminiscence group. Thus, whilst the intervention seemed to be effective, there was no evidence that it was any more effective than the reminiscence activities. The one study that showed no significant effects (Klinedinst \& Resnick, 2016) was rated as being of moderate quality, but comprised of just a single group of ten participants, resulting in low power and an inability to distinguish any effects of the intervention from unrelated issues.

In sum, whilst there is some evidence that interventions in this group could be at least as effective as other types of intervention as improving wellbeing, the strength of these conclusions is limited by a relative lack of power and/or comparisons against appropriate passive and active control groups in the studies.

\section{Interventions that trained participants in a new skill}

Three studies evaluated interventions that trained participants in a new skill (Kiyota, 2009; Kosmat \& Vranic, 2017; Sollami et al., 2017). Only one study, in which participants learnt to care for, train, and play with a therapy dog, demonstrated significant findings (Sollami et al., 2017). Whilst these effects were observed across all five wellbeing outcome measures, the quality of the study was rated as low, and the intervention was compared to a passive (usual care) rather than an active control group. As such, it is difficult to determine which element(s) of the intervention were responsible for any improvements seen. Neither of the other two studies showed any significant pre-post intervention changes in wellbeing in any of the intervention or control groups. These interventions, which involved learning to care for house plants (Kiyota, 2009) and a group dance training programme (Kosmat \& Vranic, 2017), were both rated as being of moderate quality, but still had relatively small sample sizes of 29 (spread across three groups) and 24 (across two groups), respectively. In sum, conclusions about the effectiveness of this group of interventions are currently limited by the lack of good quality, and well-powered studies.

\section{Discussion and Implications}

This review presented an overview of the nature of purposeful activity interventions that have been evaluated within the 'oldest old' age group of older adults, as well as a synthesis of 
evidence of their effectiveness. We identified two broad groups of intervention: (1) interventions that assigned participants a specific functional role, including becoming a volunteer or a mentor to others; (2) interventions that trained participants to develop and practice a new skill, such as learning indoor gardening or dance. There was at least some evidence that both types of intervention could be effective at improving wellbeing. However, whilst the strength and quantity of evidence was greatest for interventions involving a specific functional role, conclusions about the effectiveness of both types of intervention were limited by a lack of high-quality, well-powered studies, with appropriate control conditions.

Evidence for the effectiveness of those interventions in which participants adopted a functional role is consistent with other types of studies in a wider range of populations. For example, a cross-sectional study using national survey data from 2,867 participants demonstrated that older adults who reported that they engaged in a formal helping role, such as volunteering, had significantly better self-perceived health and higher life satisfaction than those who did not (Van Willigen, 2000). Interestingly, evidence also suggests that the motives underlying volunteering appear to be important, both in terms of volunteer retention (Kritz et al., 2020) as well as the health benefits gained. For example, a longitudinal study examining the effects of self-reported volunteering and older adults' mortality risk found that those who volunteered for self-oriented reasons had a mortality risk similar to non-volunteers (Konrath, Fuhrel-Forbis, Lou, \& Brown, 2012). However, those who volunteered for other-oriented reasons, i.e., a motive that included the desire to help another person in need, had a significantly decreased mortality risk, even after controlling for factors such as age and health-risk behaviours (Konrath et al., 2012). Thus, it has been suggested that when volunteering is altruistically motivated, this may contribute to a sense of deep and lasting well-being originating from having a purpose that is 'bigger than the self', which may regulate any potential stress or burnout associated with the volunteering itself, resulting in a positive impact on overall health (e.g., Piliavin \& Siegl, 2007).

Whilst we were able to categorise the interventions into two broader groups, it is important to recognise that there was still considerable heterogeneity within each group, as well as some overlap between them. The heterogeneity was seen in the intensity and duration of interventions, as well as in the nature of the intervention and the outcome measures used to assess wellbeing, which further detracts from the strengths of conclusions that can be drawn. The complexity of the interventions also makes it difficult to identify what the active ingredients of any particular intervention might be. Thus, even for those studies that had active control groups, it is not possible to determine the extent to which any changes were due to the 
specific element under investigation, rather than other factors. To address these issues, future studies should aim to include active control groups, and also examine the mediating effects of the variables hypothesised to underlie any effects, such as self-perceptions of ageing (Huo, Soederberg Miller, Kim \& Liu, 2020), an increase in sense of purpose, or mastery of a new skill. A review of qualitative studies of these types of interventions could also provide subjective insights into the associated mechanisms and outcomes.

Whilst this review focussed on a specific age range of adults, aged 80 years and over, this 'oldest-old' group represent a highly heterogeneous population, with a wide range of, often unique, support needs (e.g., Cosco, Howse \& Brayne, 2017). Indeed, within the studies reported in this review, some samples were comprised of participants who had been diagnosed with dementia (e.g., George \& Singer, 2011) or had mild cognitive impairments (e.g., Klinedinst \& Resnick, 2016); whereas others had no known cognitive impairment (e.g., Kosmat \& Vranic, 2017). The level of physical functioning and support needs of participants was also variable between studies. For example, some studies were comprised of participants residing in nursing homes, who typically require a higher level of care due to poorer functioning (e.g., Kiyota, 2009; Sollami et al., 2017), whereas others resided in assisted-living facilities with less complex support needs and a greater level of independence. For example, participants in the dance intervention needed to have a reasonable level of mobility and no physical health conditions that could have precluded their participation in the program (Kosmat \& Vranic, 2017). Evidence suggests that the more heterogeneous the population, the more difficult it is both to detect and to understand the intervention effects (e.g., Ferrucci et al. 2004). Furthermore, this heterogeneity facilitates the need for interventions to be individualised and tailored to the needs of each recipient (e.g., adapted to match their functional level), which in turn can lead to difficulty understanding the components or combination of components underlying the effect, or lack thereof (Freedman et al., 2006). Future studies, with larger sample sizes, could address this by examining the moderating effects of key demographic characteristics and baseline variables.

Despite the heterogeneity of participants in the studies, it is notable that the participants of all studies were based in residential care settings. As such, the findings, and indeed the interventions, may not be generalizable to community-dwelling adults of the same age range. Future research should therefore seek to develop, and evaluate, interventions that are suited to community-dwelling populations.

The overall quality of studies presented within the current review was variable. However, certain aspects of the criteria may have been difficult to achieve in psychosocial 
intervention studies with the oldest-old. For example, where there were high withdrawal rates, this was often due to unavoidable reasons, such as participant illness and death. In addition, the blinding of participants to the intervention aims may not always have been possible due to participants needing to have understood the nature of the intervention in order to demonstrate capacity to provide informed consent and meaningfully participate. However, for many of the quality assessment criteria that were not fulfilled, the reason was lack of reporting and insufficient information contained within the study reports. For example, the consideration of key confounding variables was consistently under-reported. In order to improve the quality of research in this area, there is a need for more robust studies with greater adherence to reporting standards, such as the Consolidated Standards of Reporting Trials (CONSORT; Begg et al., 1996).

\section{Limitations of the Review Methods}

There were some limitations of the current review. First, due to the lack of consensus regarding a definition of 'purposeful activity', as well as a lack of consistency with which relevant interventions are described within the literature, it was difficult to develop a search strategy that was sufficiently sensitive. To address this, we implemented a broad search strategy and carried out inter-rater reliability checks to ensure accurate and rigorous screening. However, it is still possible that relevant studies may have been missed. Second, whilst one unpublished doctoral dissertation was identified (Kiyota, 2009), an exhaustive search of the grey literature was not undertaken. Unpublished research is more likely to report null findings (e.g., Emerson et al., 1990), therefore the possibility of publication bias within this review must be acknowledged. Finally, only studies that were published in English were included in this review, which may have resulted in relevant studies published in other languages being overlooked.

\section{Implications for Policy and Future Research}

Whilst it is acknowledged that the conclusions from this review are tentative due to a lack of strong evidence, the most compelling evidence was for those interventions that provided a functional role. Based on this, it is recommended that long-term care facilities should consider offering opportunities for residents to engage in volunteer and mentoring activities in addition to the recreational activities typically offered in such settings. To achieve this, it may be beneficial for long-term care facilities to form links with established community groups and third-sector organisations in order to identify appropriate roles for their elderly residents. Staff 
members and carers would be instrumental in identifying community-based organisations that could appropriately support residents to participate in volunteering activities, and in addressing potential barriers to engagement. It would also be useful to monitor the longer-terms impact of these opportunities on residents' health, wellbeing, and quality of life in order to inform future health policy in this area.

The review demonstrated that the evidence for the effectiveness of skills-based training interventions for improving the psychological wellbeing and quality of life for the oldest-old was sparse. However, the potential benefits of these interventions should not be disregarded. Considerably more research is needed to explore the different contingencies of skills training interventions for the oldest-old. As a starting point, it is recommended that future research in this area should be service-user informed, for example, by conducting qualitative interviews with the oldest-old as an initial step to ascertain what types of activities or skills they would be interested in receiving formal training in, and how the training may need to be adapted to meet their needs. 


\section{References}

An, S., \& Jang, Y. (2018). The role of social capital in the relationship between physical constraint and mental distress in older adults: a latent interaction model. Aging \& Mental Health, 22(2), 245-249. doi: 10.1080/13607863.2016.1247431

Armijo-Olivo, S., Stiles, C. R., Hagen, N. A., Biondo, P. D., \& Cummings, G. G. (2012). Assessment of study quality for systematic reviews: a comparison of the Cochrane Collaboration Risk of Bias Tool and the Effective Public Health Practice Project Quality Assessment Tool. Journal of Evaluation in Clinical Practice, 18(1), 12-18. doi: $10.1111 / \mathrm{j} .1365-2753.2010 .01516$

Begg, C., Cho, M., Eastwood, S., Horton, R., Moher, D., Olkin, I., \& Stroup, D. F. (1996). Improving the quality of reporting of randomized controlled trials: the CONSORT statement. Journal of the American Medical Association, 276(8), 637-639. doi: 10.1001/jama.1996.03540080059030

Bronk, K. C. (2014). Purpose across the lifespan. In Purpose in Life (pp. 69-89). Dordrecht, Netherlands: Springer.

Brown, L.J.E., \& Astell, A. (2012). Assessing mood in older adults: a conceptual review of methods and approaches. International Psychogeriatrics, 24, 1197-1206. doi:10.1017/S1041610212000075

Cosco, T. D., Howse, K., \& Brayne, C. (2017). Healthy ageing, resilience and wellbeing. Epidemiology and Psychiatric Sciences, 26(6), 579-583. doi: $10.1017 / \mathrm{S} 2045796017000324$

Degnan, A., Berry, K., Sweet, D., Abel, K., Crossley, N., \& Edge, D. (2018). Social networks and symptomatic and functional outcomes in schizophrenia: a systematic review and meta-analysis. Social Psychiatry and Psychiatric Epidemiology, 53(9), 873-888. doi: $10.1007 / \mathrm{s} 00127-018-1552-8$

Depp, C.A. \& Jeste, D.V. (2006). Definitions and predictors of successful aging: a comprehensive review of larger quantitative studies. American Journal of Geriatric Psychiatry, 14, 6-20. doi: 10.1097/01.JGP.0000192501.03069

Depp, C., Vahia, I. V., \& Jeste, D. (2010). Successful aging: focus on cognitive and emotional health. Annual Review of Clinical Psychology, 6, 527-550. doi: 10.1146/annurev.clinpsy.121208.131449

Femia, E. E., Zarit, S. H., \& Johansson, B. (2001). The disablement process in very late life: a study of the oldest-old in Sweden. The Journals of Gerontology Series B: Psychological Sciences and Social Sciences, 56(1), 12-23. doi: 10.1093/geronb/56.1.P12

Ferrucci, L., Guralnik, J. M., Studenski, S., Fried, L. P., Cutler, G. B., \& Walston, J. D. (2004). Designing randomized, controlled trials aimed at preventing or delaying functional decline and disability in frail, older persons: A consensus report. Journal of the American Geriatrics Society, 52(4), 625-634. doi: 10.1111/j.1532-5415.2004.52174

Fortin, M., Bravo, G., Hudon, C., Vanasse, A., \& Lapointe, L. (2005). Prevalence of multimorbidity among adults seen in family practice. The Annals of Family Medicine, 3(3), 223-228. doi: 10.1370/afm.272 
Freedman, V. A., Hodgson, N., Lynn, J., Spillman, B. C., Waidmann, T., Wilkinson, A. M., \& Wolf, D. A. (2006). Promoting declines in the prevalence of late-life disability: comparisons of three potentially high-impact interventions. The Milbank Quarterly, 84(3), 493-520. doi: 10.1111/j.1468-0009.2006.00456

George, D. R., \& Singer, M. E. (2011). Intergenerational volunteering and quality of life for persons with mild to moderate dementia: results from a 5-month intervention study in the United States. The American Journal of Geriatric Psychiatry, 19(4), 392-396. doi: 10.1097/JGP.0b013e3181f17f20

Heaven, B., Brown, L. J., White, M., Errington, L., Mathers, J. C., \& Moffatt, S. (2013). Supporting well-being in retirement through meaningful social roles: Systematic review of intervention studies. The Milbank Quarterly, 91(2), 222-287. doi: 10.1111/milq.12013

Higgins, J., \& Green, S. (2008). Cochrane Handbook for Systematic Reviews of Interventions. Chichester, UK: Wiley.

Huo, M., Soederberg Miller, L.M., Kim, K. \& Liu, S. (2020). Volunteering, self-perceptions of aging, and mental health in later life. The Gerontologist. Advance online publication. doi:10.1093/geront/gnaa164

Irving, J., Davis, S., \& Collier, A. (2017). Aging with purpose: Systematic search and review of literature pertaining to older adults and purpose. The International Journal of Aging and Human Development, 85(4), 403-437. doi: 10.1177/0091415017702908

Kim, E. S., Sun, J. K., Park, N., Kubzansky, L. D., \& Peterson, C. (2013). Purpose in life and reduced risk of myocardial infarction among older US adults with coronary heart disease: a two-year follow-up. Journal of Behavioural Medicine, 36(2), 124-133. doi: 10.1007/s10865-012-9406-4

Kiyota, E. (2009). People-nature Interactions: The Therapeutic Role of Nature in Elderly Residents' Everyday Experience in a Long-Term Care Facility (Unpublished doctoral dissertation, University of Wisconsin, Milwaukee). Retrieved from https://search.proquest.com/openview/2d6971fbf75bb3a9aa95940d37799ee7/1?pqorigsite $=$ gscholar \&cbl $=18750 \&$ diss $=y$

Klinedinst, N. J., \& Resnick, B. (2016). The Volunteering-in-Place (VIP) Program: Providing meaningful volunteer activity to residents in assisted living with mild cognitive impairment. Geriatric Nursing, 37(3), 221-227. doi: 10.1016/j.gerinurse.2016.02.012

Konrath, S., Fuhrel-Forbis, A., Lou, A., \& Brown, S. (2012). Motives for volunteering are associated with mortality risk in older adults. Health Psychology, 31(1), 87. doi: $10.1037 / \mathrm{a} 0025226$

Kosmat, H., \& Vranic, A. (2017). The efficacy of a dance intervention as cognitive training for the old-old. Journal of Aging and Physical Activity, 25(1), 32-40. doi: 10.1123/japa.2015-0264

Kritz, M., Ntoumanis, N., Mullan, B., Stathi, A. \& Thøgersen-Ntoumani, C. (2020). Volunteer motivation and retention of older peer walk leaders: a 4-month long investigation. The Gerontologist. Advance online publication. doi:10.1093/geront/gnaa159. 
Landi, F., Liperoti, R., Russo, A., Capoluongo, E., Barillaro, C., Pahor, M., \& Onder, G. (2010). Disability, more than multimorbidity, was predictive of mortality among older persons aged 80 years and older. Journal of Clinical Epidemiology, 63(7), 752-759. doii: 10.1016/j.jclinepi.2009.09.007

Mays, N., Roberts, E., \& Popay, J. (2001). Synthesising research evidence. In Fulop, N., Allen, P., Clarke, A., \& Black, N. (Eds.) Studying the organisation and delivery of health services: Research methods (pp.188-220). London, UK: Routledge.

McKnight, P. E., \& Kashdan, T. B. (2009). Purpose in life as a system that creates and sustains health and well-being: An integrative, testable theory. Review of General Psychology, 13(3), 242-251. doi: 10.1037/a0017152

Morrow-Howell, N., Hinterlong, J., Rozario, P. A., \& Tang, F. (2003). Effects of volunteering on the well-being of older adults. The Journals of Gerontology Series B: Psychological Sciences and Social Sciences, 58(3), 137-145. doi: 10.1093/geronb/58.3.S137

Neugarten, B. L., Havinghurst, R. J., \& Tobin, S. C. (1961) The measurement of life satisfaction. Journal of Gerontology, 16, 134-143. Retrieved from https://journals.sagepub.com/doi/pdf/10.2466/pr0.1970.27.1.75

Ohrnberger, J., Fichera, E., \& Sutton, M. (2017). The relationship between physical and mental health: A mediation analysis. Social Science \& Medicine, 195, 42-49. doi: 10.1016/j.socscimed.2017.11.008

Pierce, D. (2001). Untangling occupation and activity. American Journal of Occupational Therapy, 55(2), 138-146. doi: 10.5014/ajot.55.2.138

Piliavin, J. A., \& Siegl, E. (2007). Health benefits of volunteering in the Wisconsin Longitudinal Study. Journal of Health and Social Behaviour, 48, 450 - 464. doi: 10.1177/002214650704800408

Pinquart, M. (2002). Creating and maintaining purpose in life in old age: A metaanalysis. Ageing International, 27(2), 90-114. doi: 10.1007/s12126-002-1004-2

Popay, J., Roberts, H., Sowden, A., Petticrew, M., Arai, L., Rodgers, M., \& Duffy, S. (2006). Guidance on the conduct of narrative synthesis in systematic review: A product from the ESRC methods programme. Retrieved from https://pdfs.semanticscholar.org/ed8b/23836338f6fdea0cc55e161b0fc5805f9e27.pdf

Safavi, R., Berry, K., \& Wearden, A. (2017). Expressed emotion in relatives of persons with dementia: a systematic review and meta-analysis. Aging \& Mental Health, 21(2), 113124.doi: 10.1080/13607863.2015.1111863

Sarvimäki, A., \& Stenbock-Hult, B. (2000). Quality of life in old age described as a sense of well-being, meaning and value. Journal of Advanced Nursing, 32(4), 1025-1033. doi: 10.1046/j.1365-2648.2000.01568

Schulenberg, S. E., \& Melton, A. M. (2010). A confirmatory factor-analytic evaluation of the purpose in life test: Preliminary psychometric support for a replicable two-factor model. Journal of Happiness Studies, 11(1), 95-111. doi: 10.1007/s10902-008-9124-3 
Shmotkin, D., Blumstein, T., \& Modan, B. (2003). Beyond keeping active: Concomitants of being a volunteer in old-old age. Psychology and Aging, 18(3), 602-607. doi: 10.1037/0882-7974.18.3.602

Sollami, A., Gianferrari, E., Alfieri, M., Artioli, G., \& Taffurelli, C. (2017). Pet therapy: an effective strategy to care for the elderly? An experimental study in a nursing home. Acta Biomedica: Atenei Parmensis, 88(1), 25-31. doi: 10.23750/abm.v88i1 -S.6281

Thomas, B. H., Ciliska, D., Dobbins, M., \& Micucci, S. (2004). A process for systematically reviewing the literature: providing the research evidence for public health nursing interventions. Worldviews on Evidence-Based Nursing, 1(3), 176-184. doi: $10.1111 / \mathrm{j} .1524-475 X .2004 .04006$

United Nations, Department of Economic and Social Affairs, Population Division (2017). World Population Ageing - Highlights. Retrieved from https://www.un.org/en/development/desa/population/publications/pdf/ageing/WPA2017_ Highlights.pdf

Van Malderen, L., De Vriendt, P., Mets, T., Verté, D., \& Gorus, E. (2017). Experiences and effects of structurally involving residents in the nursing home by means of participatory action research: A mixed method study. Journal of the American Medical Directors Association, 18(6), 495-502. doi: 10.1016/j.jamda.2016.12.072

Van Willigen, M. (2000). Differential benefits of volunteering across the life course. The Journals of Gerontology Series B: Psychological Sciences and Social Sciences, 55(5), 308-318. doi: 10.1093/geronb/55.5.S308

Verbrugge, L. M., \& Jette, A. M. (1994). The disablement process. Social Science \& Medicine, 38(1), 1-14. doi: 10.1016/0277-9536(94)90294-1

Verropoulou, G., \& Tsimbos, C. (2017). Disability trends among older adults in ten European countries over 2004-2013, using various indicators and Survey of Health, Ageing and Retirement in Europe (SHARE) data. Ageing \& Society, 37(10), 2152-2182. doi: 10.1017/S0144686X16000842

Yuen, H. K. (2003). Impact of an altruistic activity on life satisfaction in institutionalized elders: A pilot study. Physical \& Occupational Therapy in Geriatrics, 20(3-4), 125-135. doi: 10.1080/J148v20n03_08

Yuen, H. K., Huang, P., Burik, J. K., \& Smith, T. G. (2008). Impact of participating in volunteer activities for residents living in long-term-care facilities. American Journal of Occupational Therapy, 62(1), 71-76. doi: 10.5014/ajot.62.1.71

Zhang, R., Ewalds-Kvist, B. M., Li, D., \& Jiang, J. (2019). Chinese Students' Satisfaction with Life Relative to Psychological Capital and Mediated by Purpose in Life. Current Psychology, 38(1), 260-271. doi: 10.1007/s12144-018-9849 
Figure 1. Preferred Reporting Items for Systematic Reviews and Meta-Analyses (PRISMA) flow diagram depicting the systematic search process.

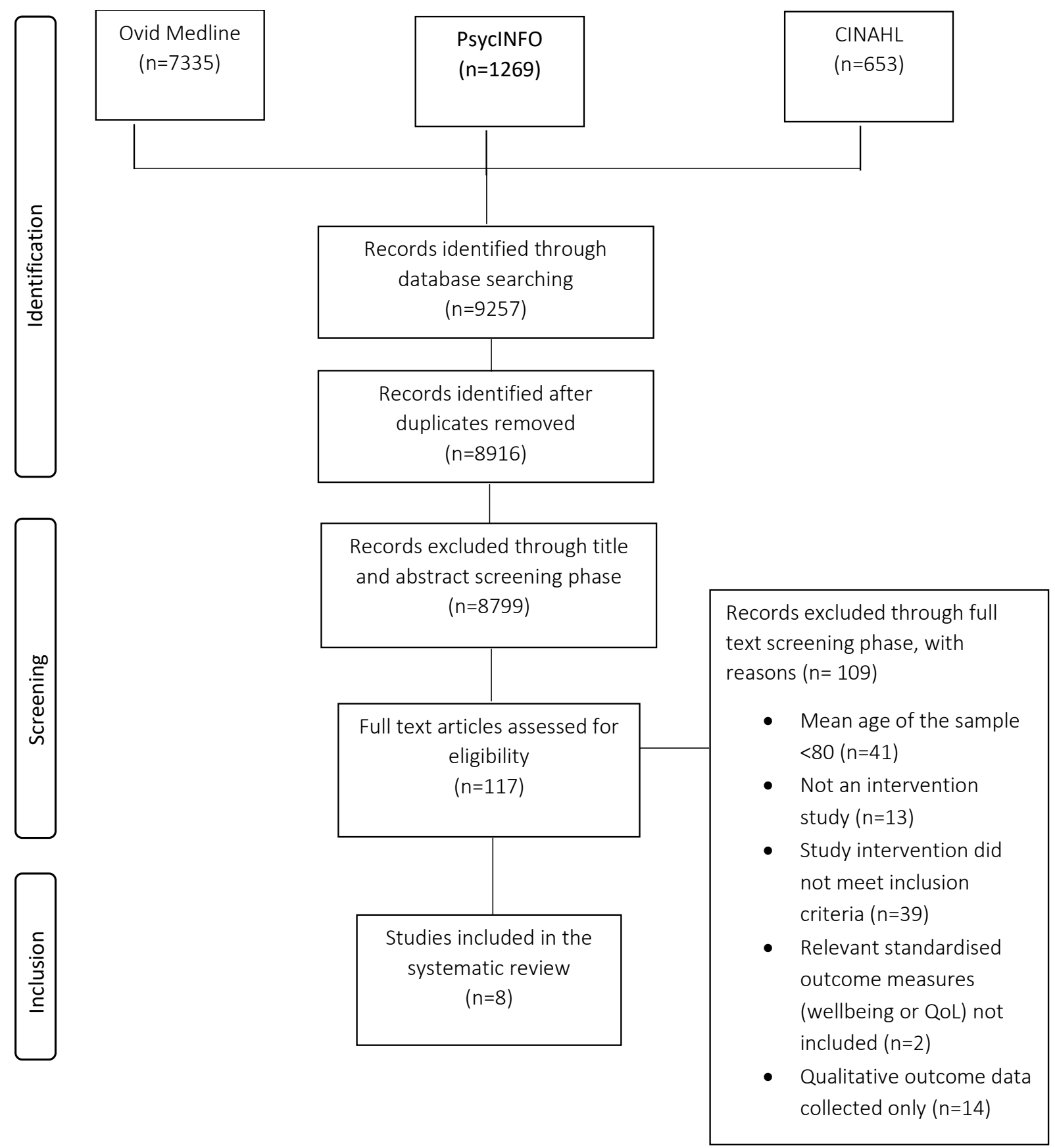


Table 1. Characteristics of included studies.

\begin{tabular}{|c|c|c|c|c|c|c|c|c|}
\hline $\begin{array}{l}\text { Author, } \\
\text { Year, } \\
\text { Country }\end{array}$ & $\begin{array}{l}\text { Study } \\
\operatorname{Aim}(s)\end{array}$ & Sample & $\begin{array}{l}\text { Study } \\
\text { Design }\end{array}$ & Intervention & $\begin{array}{l}\text { Control } \\
\text { Condition }\end{array}$ & $\begin{array}{l}\text { Relevant } \\
\text { Outcome } \\
\text { Measures }\end{array}$ & Main Findings & $\begin{array}{l}\text { Global } \\
\text { Quality } \\
\text { Rating }\end{array}$ \\
\hline
\end{tabular}

Interventions that assigned participants a specific functional role

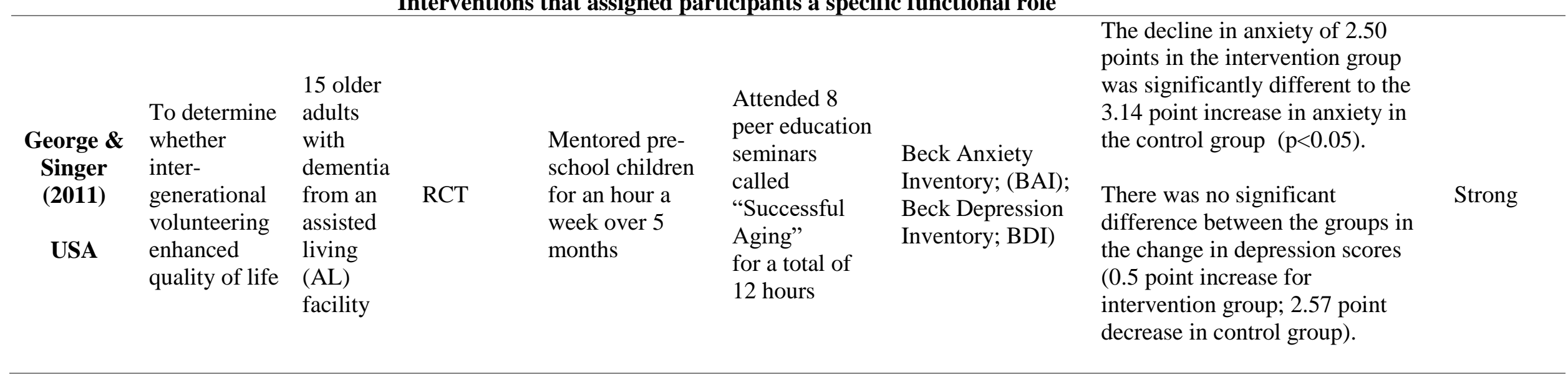


(1) To

establish

$\begin{array}{ll}\text { Klinedinst } & \text { feasibility of } \\ \text { volunteering }\end{array}$

\& Resnick

(2016)

program

USA

(2) To

evaluate

impact on

wellbeing
10

assisted Cohort Volunteering in

living study

(AL)

residents
Place (VIP)

program

between 1-3

days per week

over 6 months
Depression

(PHQ-9); Purpose

in Life (Ryff's

Scales of

Psychological

Well-Being);

Dispositional

Resilience Scale;

AL Resident Life

Satisfaction Tool
No significant effects on any outcome at 3- or 6-mth follow-ups

Moderate

\section{To examine}

the effects of

Van Participatory

Malderen Action

et al., Research

2017 (PAR)

within a

Belgium

home on

quality of life

Weekly

Participatory

88

residents

from 3

nursing

homes

RCT

Action Research

group sessions

over 6 months,

where residents

worked with a

staff member

and researcher

to identify ways

of improving the nursing home.
Active

Control:

weekly group Quality of Life

reminiscence using The

sessions over 6 Anamnestic

months

Comparative Self-

Assessment scale

Passive (ACSA)

Control: usual

care
The increase in ACSA score from

baseline to 6-month post-test was significantly greater in the

intervention and active control groups than in the passive control Moderate group. However, there were no significant differences in the amount of change experienced in the intervention group compared to the control groups. 


\begin{tabular}{|c|c|c|c|c|c|c|c|c|}
\hline $\begin{array}{c}\text { Yuen } \\
(\mathbf{2 0 0 3 )} \\
\text { USA }\end{array}$ & $\begin{array}{l}\text { To evaluate } \\
\text { the impact } \\
\text { of } \\
\text { participation } \\
\text { in an } \\
\text { altruistic } \\
\text { activity on } \\
\text { wellbeing }\end{array}$ & $\begin{array}{l}18 \text { care } \\
\text { home } \\
\text { residents }\end{array}$ & $\begin{array}{l}\text { Controlled } \\
\text { clinical } \\
\text { trial }\end{array}$ & $\begin{array}{l}\text { One-on-one } \\
\text { mentoring } \\
\text { conversational } \\
\text { skills to English } \\
\text { as a Second } \\
\text { Language (ESL) } \\
\text { students in an } \\
\text { hour session for } \\
1-3 \text { weeks }\end{array}$ & Usual care & $\begin{array}{l}\text { The Life } \\
\text { Satisfaction } \\
\text { Index-A (LSI-A) }\end{array}$ & $\begin{array}{l}\text { After controlling for baseline } \\
\text { score, the mean life satisfaction } \\
\text { score of the intervention group } \\
\text { was significantly higher than the } \\
\text { control group } 1.5-2 \text { months after } \\
\text { baseline. In addition, the } \\
\text { intervention group showed a } \\
\text { significant pre-post improvement } \\
\text { in LSI-A score, whereas no } \\
\text { significant change was found in } \\
\text { the control group. }\end{array}$ & Weak \\
\hline $\begin{array}{l}\text { Yuen et } \\
\text { al., } 2008 \\
\text { USA }\end{array}$ & $\begin{array}{l}\text { To } \\
\text { investigate } \\
\text { the effect of } \\
\text { a volunteer } \\
\text { activity on } \\
\text { wellbeing }\end{array}$ & $\begin{array}{l}28 \text { care } \\
\text { home } \\
\text { residents }\end{array}$ & $\mathrm{RCT}$ & $\begin{array}{l}\text { One-to-one } \\
\text { mentoring } \\
\text { conversational } \\
\text { skills to ESL } \\
\text { students in an } \\
\text { hour twice per } \\
\text { week for } 12 \\
\text { weeks }\end{array}$ & Usual care & $\begin{array}{l}\text { The Geriatric } \\
\text { Depression Scale; } \\
\text { Life Satisfaction } \\
\text { Index-A }\end{array}$ & $\begin{array}{l}\text { A multivariate global statistical } \\
\text { test of combined effects of the } \\
\text { two relevant outcome measures } \\
\text { plus a measure of self-rated health } \\
\text { showed significant increases in } \\
\text { both groups from baseline to post- } \\
\text { intervention, and from baseline to } \\
\text { 3-month follow up. However, } \\
\text { there were no significant } \\
\text { differences between the groups. }\end{array}$ & Strong \\
\hline
\end{tabular}

Interventions that trained participants in the development of a new skill 


\begin{tabular}{|c|c|c|c|c|c|c|c|c|}
\hline $\begin{array}{l}\text { Kiyota } \\
(2009) \\
\text { Canada }\end{array}$ & $\begin{array}{l}\text { To determine } \\
\text { whether } \\
\text { caring for } \\
\text { house } \\
\text { plants } \\
\text { improved } \\
\text { wellbeing }\end{array}$ & $\begin{array}{l}29 \\
\text { nursing } \\
\text { home } \\
\text { residents }\end{array}$ & $\begin{array}{l}\text { Cluster } \\
\text { RCT }\end{array}$ & $\begin{array}{l}\text { Learned how to } \\
\text { care for house } \\
\text { plants and } \\
\text { carried out } \\
\text { various } \\
\text { activities to } \\
\text { grow and care } \\
\text { for plant over } 6 \\
\text { weeks }\end{array}$ & $\begin{array}{l}\text { Passive } \\
\text { Interaction } \\
\text { Group: } \\
\text { exposed to } \\
\text { house plants in } \\
\text { the communal } \\
\text { area } \\
\text { Control } \\
\text { Group: no } \\
\text { exposure }\end{array}$ & $\begin{array}{l}\text { Geriatric } \\
\text { Depression Scale }\end{array}$ & $\begin{array}{c}\text { No statistically significant } \\
\text { differences in levels } \\
\text { of depression in any group across } \\
\text { the intervention period }\end{array}$ & Moderate \\
\hline $\begin{array}{l}\text { Kosmat } \\
\text { \& Vranic } \\
\text { (2017) } \\
\text { Croatia }\end{array}$ & $\begin{array}{l}\text { To evaluate } \\
\text { the impact of } \\
\text { a dance } \\
\text { intervention } \\
\text { on wellbeing } \\
\text { and } \\
\text { cognitive } \\
\text { functioning }\end{array}$ & $\begin{array}{l}24 \text { care } \\
\text { home } \\
\text { residents }\end{array}$ & $\mathrm{RCT}$ & $\begin{array}{l}\text { Group dance } \\
\text { training } \\
\text { program; } \\
\text { learned } \\
\text { choreography } \\
\text { with dancing } \\
\text { instructor for } 45 \\
\text { mins per week } \\
\text { over } 10 \text { weeks }\end{array}$ & $\begin{array}{l}\text { Met with the } \\
\text { researcher in } \\
\text { small groups } \\
\text { for } 45 \text { mins } \\
\text { per week over } \\
10 \text { weeks to } \\
\text { discuss various } \\
\text { topics }\end{array}$ & $\begin{array}{l}\text { Satisfaction with } \\
\text { Life Scale } \\
\text { (SWLS); General } \\
\text { Self-Efficacy } \\
\text { Scale }\end{array}$ & $\begin{array}{c}\text { For satisfaction with life, there } \\
\text { was a marginally significant } \\
\text { group x session interaction ( } p \\
=.058) \text {. Post-hoc analysis showed } \\
\text { that this was due to a significant } \\
\text { decline in the control group from } \\
\text { post-test to 5-month follow-up. } \\
\text { Neither group showed a } \\
\text { significant change in self-efficacy } \\
\text { over time. }\end{array}$ & Moderate \\
\hline $\begin{array}{l}\text { Sollami et } \\
\text { al., } 2017 \\
\text { Italy }\end{array}$ & $\begin{array}{l}\text { To ascertain } \\
\text { the } \\
\text { effectiveness } \\
\text { of pet } \\
\text { therapy in } \\
\text { improving } \\
\text { well-being }\end{array}$ & $\begin{array}{l}28 \\
\text { nursing } \\
\text { home } \\
\text { residents }\end{array}$ & $\mathrm{RCT}$ & $\begin{array}{l}\text { Animal assisted } \\
\text { intervention, in } \\
\text { which } \\
\text { participants ; } \\
\text { learned to } \\
\text { perform } \\
\text { activities with a } \\
\text { therapy dog, } \\
\text { including giving } \\
\text { commands, and } \\
\text { playing with and }\end{array}$ & Usual care & $\begin{array}{l}\text { Short-Form } \\
\text { Geriatric } \\
\text { Depression Scale; } \\
\text { Apathy } \\
\text { Evaluation Scale; } \\
\text { Quality of Life in } \\
\text { Dementia Scale; } \\
\text { Hamilton Anxiety } \\
\text { Scale (HAM-A); } \\
\text { UCLA Loneliness } \\
\text { Scale. }\end{array}$ & $\begin{array}{l}\text { Significant improvements were } \\
\text { seen in the intervention group for } \\
\text { all outcome measures from pre to } \\
\text { post-intervention. The amount of } \\
\text { change was significantly greater } \\
\text { in the experimental group than the } \\
\text { control group for each variable. }\end{array}$ & Weak \\
\hline
\end{tabular}


taking care of it,

over 16 twice-

weekly, one-

hour sessions 


\section{Supplementary Table 1: Full list of systematic review search terms}

1. exp "Aged, 80 and over"/ or exp Aged/ or exp Aging/ or older adult*.mp.

2. senior citizen*.mp.

3. exp Frail Elderly/

4. dementia.mp. or exp Dementia/

5. exp Nursing Homes/ or exp Homes for the Aged/ or nursing home*.mp.

6. care home*.mp.

7. long-term care facilit*.mp. or exp Long-Term Care/

8. exp Residential Facilities/ or residential care*.mp.

9. retirement home*.mp.

10. oldest*.mp.

11. senior*.mp. or exp Senior Centers/

12. elder*.mp.

13. Frailty/ or frail*.mp.

14. geriatric*.mp. or exp Geriatric Assessment/ or exp Geriatric Psychiatry/ or exp Geriatric Nursing

15. 1 or 2 or 3 or 4 or 5 or 6 or 7 or 8 or 9 or 10 or 11 or 12 or 13 or 14

16. intervention.mp.

17. program*.mp. or exp Program Evaluation/

18. therap*.mp.

19. treatment.mp. or exp Therapeutics/

20. exp Evaluation Studies as Topic/ or evaluat*.mp.

21. effectiveness.mp. or exp Comparative Effectiveness Research/

22. exp Treatment Outcome/ or randomised controlled trial*.mp. or exp Randomized Controlled Trials as Topic/

23. exp Cohort Studies/ or cohort stud*.mp.

24. 16 or 17 or 18 or 19 or 20 or 21 or 22 or 23

25. meaningful activit*.mp.

26. purposeful activit*.mp.

27. role*.mp.

28. meaning*.mp.

29. 27 and 28

30. purpose*.mp.

31. 27 and 30

32. social*.mp.

33. 27 and 32

34. exp Volunteers/ or volunt*.mp.

35. vocation*.mp.

36. exp Rehabilitation, Vocational/

37. exp Occupational Therapy/

38. exp Animal Assisted Therapy/

39. life purpose.mp.

40. purpose in life.mp.

41. sense of purpose.mp.

42.25 or 26 or 29 or 31 or 33 or 34 or 35 or 36 or 37 or 38 or 39 or 40 or 41

43. 15 and 24 and 42

44. quality of life.mp. or exp "Quality of Life"/

45. well-being.mp. 
46. wellbeing.mp.

47. psychological wellbeing.mp. or exp Adaptation, Psychological/

48. exp Personal Satisfaction/ or life satisfaction.mp.

49. satisfaction with life.mp.

50. mood.mp. or exp Affect/

51. happiness.mp. or exp Happiness/

52.44 or 45 or 46 or 47 or 48 or 49 or 50 or 51

53. and 52

54. limit 53 to ("all aged (65 and over)" and English) 
Supplementary Table 2. Quality Assessment of included studies

EPHPP Section Ratings (strong/moderate/weak)

\begin{tabular}{|c|c|c|c|c|c|c|c|c|}
\hline $\begin{array}{l}\text { Author, } \\
\text { Year }\end{array}$ & $\begin{array}{l}\text { Selection } \\
\quad \text { Bias }\end{array}$ & $\begin{array}{l}\text { Study } \\
\text { design }\end{array}$ & Confounders & Blinding & $\begin{array}{c}\text { Data } \\
\text { collection }\end{array}$ & Analysis & $\begin{array}{l}\text { Withdrawals } \\
\text { and dropouts }\end{array}$ & $\begin{array}{l}\text { Global } \\
\text { Rating }\end{array}$ \\
\hline & \multicolumn{8}{|c|}{ Interventions that assigned a specific functional role } \\
\hline $\begin{array}{l}\text { George \& } \\
\text { Singer } \\
\text { (2011) }\end{array}$ & Moderate & Strong & Strong & Moderate & Strong & Moderate & Strong & Strong \\
\hline $\begin{array}{l}\text { Klinedinst } \\
\text { \& Resnick } \\
\text { (2016) }\end{array}$ & Moderate & Moderate & Weak & Moderate & Strong & Moderate & Strong & Moderate \\
\hline $\begin{array}{l}\text { Van } \\
\text { Malderen } \\
\text { et al., } 2017\end{array}$ & Moderate & Strong & Strong & Moderate & Strong & Moderate & Weak & Moderate \\
\hline $\begin{array}{l}\text { Yuen } \\
(2003)\end{array}$ & Moderate & Strong & Weak & Moderate & Strong & Moderate & Weak & Weak \\
\hline \multirow[t]{2}{*}{$\begin{array}{l}\text { Yuen et al., } \\
2008\end{array}$} & Moderate & Strong & Strong & Moderate & Strong & Moderate & Moderate & Strong \\
\hline & \multicolumn{8}{|c|}{ Interventions that trained participants in a new skill } \\
\hline $\begin{array}{l}\text { Kiyota } \\
(2009)\end{array}$ & Moderate & Strong & Weak & Moderate & Strong & Moderate & Moderate & Moderate \\
\hline $\begin{array}{l}\text { Kosmat \& } \\
\text { Vranic } \\
\text { (2017) }\end{array}$ & Moderate & Strong & Weak & Moderate & Strong & Moderate & Strong & Moderate \\
\hline $\begin{array}{l}\text { Sollami et } \\
\text { al., } 2017\end{array}$ & Moderate & Strong & Weak & Moderate & Strong & Strong & Weak & Weak \\
\hline
\end{tabular}

